\title{
A EDUCAÇÃO DE ADULTOS EM PORTUGAL E OS TRAÇOS DA POLÍTICA GLOBAL EM TEMPOS DE AUSTERIDADE
}

R. BARROS
Universidade do Algarve
rmbarros@ualg.pt
Submetido $20 / 02 / 2018-$ Aceito $06 / 03 / 2018$
DOI: $10.15628 /$ holos. 2018.6980

\section{RESUMO}

O artigo reflete acerca das condições conjunturais e influências supranacionais que permitiram a emergência de uma nova educação e formação de adultos (EFA) em Portugal. Discute-se as carateristicas e lógicas subjacentes aos dois Programas políticos nacionais que conformam a agenda deste sector no início do século XXI, nomeadamente: o i) Programa de Ação S@bert: Programa para o Desenvolvimento e Expansão da Educação e Formação de Adultos, 1999-2006; e o ii) Programa (ou Iniciativa) Novas Oportunidades, 20062012. Em ambos os enquadramentos políticos do sector a aprendizagem experiencial dos adultos é valorizada, o que representou uma sólida ancoragem do sistema EFA na lógica do reconhecimento de adquiridos experiencias. $\mathrm{O}$ que no caso de Portugal tem vindo a representar um passo em frente em termos de justiça social, dado que uma muito significativa parcela da população adulta nacional é pouco escolarizada, porém é, para além disso, subcertificada face ao seu 'saber de experiencia feito' a que se refere Paulo Freire. Tecem-se também neste texto algumas considerações críticas acerca do impacto que o paradigma hegemónico global da política pública para as estatisticas comporta para o desenvolvimento da EFA, cuja essência humanista não se compatibiliza com a formação instrumental de recursos humanos. Por fim, problematiza-se as evoluções mais recentes da nova governação global neoliberal criadora e impositora de austeridades várias a partir do seu impacto na EFA portuguesa.

PALAVRAS-CHAVE: Educação e formação de adultos, reconhecimento de adquiridos experienciais, política global neoliberal, austeridade.

\section{THE ADULT EDUCATION AND TRAINING IN PORTUGAL AND THE TRACES OF A GLOBAL POLICY IN AUSTERITY TIMES}

\begin{abstract}
In this article we make a reflection around conjectural conditions and supranational influences that allowed the emergence in Portugal of a new adult education and training (EFA). A discussion of the two national political programmes that stablish the XXI EFA agenda is made, mainly the i) Programa de Ação S@ber+: Programa para o Desenvolvimento e Expansão da Educação e Formação de Adultos, 1999-2006; and the ii) Programa (ou Iniciativa) Novas Oportunidades, 2006-2012.
\end{abstract}

In both political frameworks the experiential learning is valued, and recognition of prior learning represents the basis for the EFA system. We argue this represents a step forward in terms of social justice since the adult population in this Country is low qualified but mainly sub certified in front of the experiential knowledge they have.

We critical analyse, as well, the impact of the hegemonic political global paradigm of politics for statistics on the development of EFA, as far as the essence of the field is hardly compatible with the instrumental training of human resources. Finally we discuss recent evolutions of the new neoliberal governance that creates and imposes several austerities from the impact it had on the Portuguese EFA case.

KEYWORDS: Adult education and training, recognition of prior learning, neoliberal global policy, austerity. 


\section{PREÂMBULO: BREVES CONSIDERAÇÕES METODOLÓGICAS}

Este artigo foi redigido com base nos dados e resultados de duas investigações científicas elaboradas em função de distintos enquadramentos, nomeadamente: i) uma etnografia crítica, que foi realizada num Centro de Reconhecimento, Validação e Certificação de Competências (CRVCC) na região rural do sul de Portugal, cujo trabalho de campo foi contínuo e foi efetuado entre 2004 e 2005, no âmbito do qual foram aplicadas as técnicas da entrevista e da observação direta participante. Esta investigação compreendeu também a análise documental e de discurso e ocorreu no contexto da realização de um doutoramento na Universidade do Minho (Barros, 2009a); e ii) uma investigação-ação, que se encontra em curso e vem sendo realizada num Centro para a Qualificação e o Ensino Profissional (CQEP), e agora Centro Qualifica (CQ), na região urbana do sul do país, cujo trabalho de terreno foi iniciado em 2016 e se encontra em progresso e no âmbito do qual estão a ser aplicadas as técnicas da entrevista e da observação direta nãoparticipante. Esta investigação, por sua vez, decorre no contexto do desenvolvimento de um projeto de investigação internacional financiado pelo Programa Erasmus + (2015-2018: Projeto 479A0AF7447AC35B, EURE.K - Validation des Compétences-clés Européennes).

\section{A EMERGÊNCIA DE UMA NOVA EDUCAÇÃO E FORMAÇÃO DE ADULTOS (EFA) EM PORTUGAL}

Dado o impacto social e mediático que teve a abrangente difusão do estudo sobre literacia em Portugal (Benavente et al., 1995), o 13 Governo constitucional (Partido Socialista) expressou preocupações com a situação depauperada da educação de adultos enquanto subsistema público de educação. E assim, foram comunicadas as linhas mestras do relançamento da educação de adultos em Portugal agora com o estatuto de opção estratégica da política educativa do Governo. Surgiram, então, diversas medidas sectoriais concretas tomadas no âmbito de um Pacto Educativo para o Futuro, que pretendeu inaugurar (sem verdadeiramente o conseguir) um novo modo de encarar os processos de tomada de decisão em educação. Emergiu a ideia de que apostar na esfera de participação da política permite, pela negociação entre interesses plurais, introduzir alterações a longo prazo com a definição sustentável de estratégias educativas que ultrapassem o imediatismo e o conjuntural. Se considerarmos que, segundo Tedesco, "situar o processo de concertação no centro das estratégias de mudança educativa não implica apenas uma mudança do ponto de vista dos métodos de acordo com os quais se lida com as estratégias de reforma. Supõe, mais do que isso, uma modificação significativa do lugar ocupado pela educação no processo de concertação social” (Tedesco, 2000, p. 165), então, percebe-se facilmente que, de modo geral, este novo figurino, na formação social portuguesa, para a elaboração das políticas públicas de educação iria suscitar grandes expetativas.

No conjunto dos dez compromissos do Pacto Educativo constavam duas ações prioritárias. Enquanto uma das ações prioritárias para o sector referiu a "adoção de medidas visando estimular a atualização, ao longo de toda a vida, do saber, do saber-fazer, do aprender-a-sercom-os-outros e do saber relacional e comportamental de toda a população, em especial dos indivíduos e dos grupos marcados por processos de exclusão social" (Pacto Educativo para o Futuro, 1996, p. 95); a outra veio, por sua vez, asseverar o "lançamento de um programa, no 
primeiro trimestre de 1996 e no âmbito do Ano Internacional da Educação e da Formação para Toda a Vida, tendente a assegurar a atualização permanente dos níveis de educação/formação da população em geral" (id., ibid.). Ambas as ações determinaram o início da decisiva articulação conceptual entre educação e formação que viria a orientar os discursos e a marcar a agenda para a educação de adultos em Portugal desde então, sob a influência (contraditória) de dois documentos de referência a nível internacional, um produzido no âmbito da UNESCO e outro no âmbito da União Europeia (UE).

Também a proclamação, pelo Parlamento e Conselho europeus, do Ano Europeu da Aprendizagem ao Longo da Vida, foi um evento europeu decisivo para o acelerar do processo de europeização das políticas educativas nacionais (Barros \& Belando-Montoro, 2013). Várias iniciativas ocorreram de que destacamos a criação de um Grupo de Trabalho de cujo labor resultou a publicação do Documento de Estratégia intitulado Uma Aposta Educativa na Participação de Todos. Neste Documento elaboraram-se dez recomendações para o desenvolvimento de um sistema de educação de adultos nacional (cf. Melo et al., 1998: 49-64), de que salientamos três: i) a recomendação que propõe o lançamento de um Programa de Desenvolvimento da Educação de Adultos que deveria assentar num fundo especificamente criado para o sector; ii) a recomendação que propõe a criação de uma estrutura organizativa, exclusiva mas largamente participada, de educação de adultos, tutelada pelo Ministério da Educação mas com autonomia; e iii) a recomendação que propõe definir e aplicar um esquema nacional de balanço de competências pessoais e de validação dos adquiridos profissionais ou de aprendizagem. A este respeito Alberto Melo frisaria que os resultados dos processos de autoaprendizagem, que decorrem nos contextos de vida e de trabalho das pessoas adultas, deveriam passar a ser reconhecidos e validados, de modo rigoroso e formal, "não só por razões de justiça social, como também por razões económicas, evitando desperdícios de tempo e de recursos públicos em formações redundantes" (Melo, 2001, p. 113).

Neste enquadramento emergiu um novo ciclo de governação educacional (um ponto de viragem) no qual a designada Educação e Formação de Adultos (EFA), passou a ser um elemento estruturante da modernização económica pós-fordista do país, e o foco de atenção política ficou prioritariamente concentrado na população adulta ativa, que evidenciava "debilidades associadas a uma mão-de-obra pouco qualificada e com pouco potencial de adaptabilidade" (Plano Nacional de Emprego, 1999, p. 76).

\section{UMA POLÍTICA PÚBLICA ASSENTE NO RECONHECIMENTO DE ADQUIRIDOS EXPERIENCIAIS: O IMPACTO DA UNESCO NO PROGRAMA DE AÇÃO S@BER+ (2001-2005)}

O Programa de Ação S@bert: Programa para o Desenvolvimento e Expansão da Educação e Formação de Adultos, 1999-2006, com que se iniciou a agenda do século XXI, apresentou e disseminou uma nova conceptualização do campo, que operaria a difícil conjugação da esfera da educação com a esfera da formação (Azevedo \& Tavares, 2015), tendo o campo, desde então, deixado, oficialmente, de ser de educação de adultos (EA) para passar a ser de educação e formação de adultos (EFA), entendendo-se por tal: 
... o conjunto das intervenções que, pelo reforço e complementaridade sinérgica com as instituições e as iniciativas em curso no domínio da educação e da formação ao longo da vida, se destinam a elevar os níveis educativos e de qualificação da população adulta e a promover o desenvolvimento pessoal, a cidadania ativa e a empregabilidade. (Melo et al, 2001, p. 11)

Assim, o panorama da oferta nacional ficou ancorado aos pressupostos do Programa de Ação S@ber+ que apresentou, inspirado nos trabalhos da quinta conferência internacionail sobre educação de adultos (CONFINTEA) promovida em 1997 pela UNESCO em Hamburgo, um conjunto diverso de finalidades e objetivos que enformaram a base dos princípios gerais para as medidas que coube depois à Agência Nacional de Educação e Formação de Adultos (ANEFA) executar. Ora, na "Agenda para o Futuro" resultante desta CONFINTEA, o tema 10 "Fomentar a cooperação e a solidariedade internacionais" ( $\$ 50$ a 53) esboça a necessidade de articular a dimensão ética com os direitos humanos, o reconhecimento do direito de aprender ao longo da vida para todas as pessoas, promovendo e valorizando as oportunidades e acentua: "A cooperação e a solidariedade internacionais devem reforçar um novo conceito da educação de adultos que seja (...) para abarcar todos os aspetos da vida, e (...) para incluir todas as áreas de atividade cultural, social e económica" (§ 50:57). Da análise deste documento, destaca-se a importância concedida aos Direitos Humanos e ao acesso de todos à educação de adultos. 0 documento sugere ainda medidas, tais como: aumentar a participação das pessoas, motivá-las para os seus interesses, aproveitar as suas experiências na construção de uma aprendizagem plena e responsável que se pretende que decorra pela vida, melhorando-a e construindo-a. Com esta visão abrangente dos saberes, deixa de haver dicotomia entre aspetos tão presentes quanto necessários ao conhecimento e à aprendizagem, tornando-os assim complementares. Se a educação formal e a não formal são tidas como determinantes neste contexto, também a informal readquire importância e peso, estabelecendo-se com base nas experiências e nas vivências das pessoas, motivações e interesses.

É, deste modo, e com este leque de influência, que a ANEFA foi criada para tutelar especificamente o sector, segundo três eixos de intervenção, designadamente: para desenvolver a motivação das pessoas adultas para a procura; para desenvolver uma oferta adequada, flexível e diversificada de educação e formação por parte das entidades formadoras; e para desenvolver a formação de agentes.

Ora, no âmbito do primeiro eixo de intervenção, dirigido ao aumento da procura, a aposta foi feita numa constante campanha de comunicação e na criação e apoio aos Clubes S@ber+ (cf. Melo et al., 2001, p. 29-32). Afigura-se-nos fundamental, neste ponto, enfatizar o paradoxo relacionado com o facto de que estes Clubes, que seriam "espaços de convívio, acolhimento, informação e orientação de adultos" (Melo et al., 2001, p. 30), e representariam o coração de um sistema EFA com possibilidades de escapar a uma mera instrumentalização do sector para fins estatísticos ou de benefício prioritário da economia, na realidade não chegaram a ser implementados consistentemente. No que se refere ao segundo eixo de intervenção, que pretendeu diversificar a oferta, a aposta surgiu maioritariamente orientada para a consolidação de um novo Sistema EFA de estrutura modelar centrado no reconhecimento, validação e certificação dos resultados da autoformação da população adulta, priorizando-se a criação das estruturas necessárias para permitir que os adquiridos informais fossem alvo de uma "análise rigorosa e reconhecimento formal, traduzidos numa validação oficial: creditação (outorga de 
créditos) com equivalência, parcial (dispensa de uma certa parte do percurso de formação) ou total (certificação, obtenção imediata de diploma oficial)" (Melo et al., 2001, p. 33). Por fim, o terceiro eixo de intervenção visou investir na "formação dos diferentes tipos de profissionais que serão responsáveis pela concretização do presente programa" (Melo et al., 2001, p. 39), que foram agrupados em quatro categorias principais: os organizadores locais, os avaliadores de competências-chave, os formadores e os responsáveis dos Clubes S@ber+.

Nestes termos, e de um modo geral, previa-se para a implementação do Programa de Ação S@ber+ (1999-2006) um papel chave para a ANEFA, quer no incremento alargado de diversas parcerias com o terceiro sector, quer na promoção de múltiplas articulações com sistemas já existentes, tais como, o sistema de formação profissional, o sistema escolar e o sistema nacional de certificação. E foi, deste modo, que surgiu no panorama português uma tutela especializada, a ANEFA, que foi concebida como estrutura de competência ao nível da conceção de metodologias de intervenção, da promoção de programas e projetos e do apoio a iniciativas da sociedade civil, no domínio da EFA, e ainda da construção gradual de um sistema de reconhecimento e validação das aprendizagens informais dos adultos (Barros, 2013a).

É assim consensual que, tanto o ano de 2000 como o ano de 2001 foram marcados, em Portugal, pela entrada em cena do funcionamento da ANEFA, tendo sido promovidas atividades afetas a novas instituições e processos educativos (Barros, 2013b) que se destinaram, no essencial, a ir ao encontro da frágil situação educacional da população ativa mediante a "criação de soluções flexíveis que articulem a educação e a formação, através de percursos organizados, a partir de processos de reconhecimento e validação de saberes adquiridos e de sistemas modulares de formação" (Anefa, 2001b, p. 29). A par do Ensino Recorrente de Adultos (ERA), básico e secundário, e da Educação Extraescolar (EEE), a estruturação da nova oferta de EFA compreendeu, a partir deste período, as seguintes modalidades: uma oferta de Cursos de Educação e Formação de Adultos (Cursos EFA); uma oferta de Ações S@ber+; e uma oferta de Reconhecimento, Validação e Certificação de Competências (RVCC). Pelo que, como resultado das políticas públicas efetivadas pela ANEFA (Lima, 2005; Rothes, 2009), se viria a constatar um real alargamento da rede nacional afeta ao sector, e portanto, antes de mais, uma expansão da diversificação da oferta, apesar da excessiva concentração de esforços numa parcela da população adulta: a população ativa.

Portanto, como tradução da diversificação nacional da oferta pública de EFA (Sistema EFA) emergiu em Portugal uma nova política pública para o sector assente no Sistema de Reconhecimento, Validação e Certificação de Competências (Sistema RVCC) que deu expressão nacional à lógica de reconhecimento de adquiridos experiencias. Iniciou-se, então, a construção (Portaria n. 1082-A/2001, DR 206, Série I-B, de 5 de Setembro) de uma Rede de Centros de Reconhecimento, Validação e Certificação de Competências ${ }^{1}$. Definiu-se que a sua equipa técnica seria composta, de um lado, pela equipa permanente, a que correspondiam: um Diretor e/ou um Coordenador/Animador Local (quando o Diretor estivesse a tempo parcial); três Profissionais de RVCC; um Administrativo; e um Técnico de Apoio à Gestão Financeira; e, de outro lado, pela equipa eventual, a que correspondiam: quatro (tempo parcial) ou dois (tempo integral) Formadores; e um Avaliador Externo. Desde então os adultos pouco escolarizados em Portugal

\footnotetext{
${ }^{1}$ Esta rede de CRVCC esteve vigente, com esta designação, entre 2001 e 2005.
} 
passaram a poder inscrever-se nas novas ofertas de EFA disponíveis, e que neste texto interessa, embora de modo sucinto, caracterizar nos seus aspetos principais.

Assim, no respeitante à oferta de Cursos EFA o que sobressaiu como mais característico e inovador foi a sua conceção (Despacho Conjunto n. 1083/2000, DR 268, Série II, de 20 de Novembro) numa lógica de dupla certificação, escolar e profissional, a partir de um modelo, que se queria integrado, baseado num Referencial de Competências-chave ${ }^{2}$, e assente no princípio transversal de iniciar cada Curso EFA com base num reconhecimento e validação das competências (RVC) adquiridas previamente por cada adulto-formando. Tratava-se, no essencial, de instituir um novo ponto de partida para os processos pedagógicos que envolviam os adultos, ambicionando-se superar "a dupla herança" (cf. Canário in Anefa, 2002e, p. 50) que vinha caracterizando a história recente do sector em Portugal, nomeadamente a da vertente escolarizante que persistiu no ensino recorrente de adultos, e a vertente da formação profissional, tendente a reproduzir uma perspetiva funcionalista da relação entre a formação e o trabalho. De acordo com Canário,

... estas duas tradições situam-se nos antípodas de uma formação que se pretende baseada na centralidade do sujeito que aprende, a partir do reconhecimento e validação de adquiridos experienciais e tendo como referência não uma listagem de conteúdos, mas sim um conjunto alargado de competências a construir. (CANÁRIO in ANEFA, 2002e, p. 50)

Neste sentido, toda a sua conceção curricular, inovadora no sector, envolveu um sistema modular criado "numa perspetiva de individualização e diferenciação dos trajetos de educaçãoformação, incluindo componentes integradas de formação profissionalizante e de formação de base que possibilitem a obtenção de uma certificação única" (Anefa, 2002c, p. 7-8), num dos três níveis $^{3}$ de certificação com que o Projeto-piloto dos Cursos EFA começaria por ser implementado no contexto português. O balanço público, resultante da análise dos primeiros 13 Cursos EFA em observação, foi apresentado, em 2002, como sendo globalmente positivo encorajando-se "o alargamento e consolidação progressivos deste novo tipo de oferta educativa, dirigido a públicos adultos não escolarizados ou cuja escolarização não cobre a educação básica obrigatória" (Canário in Anefa, 2002e, p. 49). No que respeitou à administração central desta nova oferta, destacou-se a adoção de um modelo que, de acordo com Trigo, "faz um convite e um apelo a todas as organizações da sociedade civil, acreditadas pelo INOFOR ${ }^{4}$, para desenvolverem Cursos EFA" (Trigo, 2002, p. 116), o que neste âmbito representou também a indução de novas formas de governação educacional no sector (Jessop, 1998; Barros, 2009b; Dale \& Robertson, 2014).

No referente, por seu turno, à oferta de Ações S@bert, sobressaiu como mais característico a própria estrutura destas ações de formação de curta duração, que foram

\footnotetext{
${ }^{2}$ No Referencial de Competências-chave do Ensino Básico, as áreas eram e ainda são: Cidadania e Empregabilidade (CE), Linguagem e Comunicação (LC), Matemática para a Vida (MV) e Tecnologias de Informação e Comunicação (TIC). Ver: ANEFA (2002i). Referencial de Competências-chave para a Educação e Formação de Adultos (nível básico). Lisboa: ANEFA. Disponível em: http://www.anqep.gov.pt/default.aspx

${ }^{3}$ Os três níveis são: B1, B2 e B3 concebidos como equivalentes, para todos os efeitos legais, aos 10 (quatro anos de escolaridade), 2ㅇ (seis anos de escolaridade) e 3ㅇ (nove anos de escolaridade) Ciclos do Ensino Básico Nacional.

${ }^{4}$ O INOFOR, Instituto para a Inovação na Formação, é um instituto público criado em 1997, no âmbito da então Secretaria de Estado do Trabalho e Formação - Ministério do Trabalho e Solidariedade.
} 
concebidas para abranger um vasto leque de domínios possíveis de formação, permitindo aos adultos usufruir de um ou mais módulos (de 50 horas cada) diferenciados entre si, por serem: de iniciação, de aprofundamento ou de consolidação de conhecimentos (cf. Anefa, 2001b, p. 31). A sua criação serviu de suporte às restantes ofertas, visando atingir o objetivo de "desenvolver ou reforçar competências em domínios profissionais, escolares e pessoais" (Anefa, 2001a, p. 45) e cumprir a estratégia geral afeta à criação do novo sistema EFA, designadamente: "promover a aprendizagem ao longo da vida, contribuindo para uma resposta eficaz às exigências da terciarização e do desenvolvimento económico" (Anefa, 2002a, p. 37).

Por fim, no que diz respeito, por sua vez, à oferta de Reconhecimento, Validação e Certificação de Competências (RVCC), o que sobressaiu como mais característico foi, desde logo, o seu enquadramento numa estratégica que passou por assumir que "existe em Portugal uma subcertificação" (Anefa, 2001b, p. 39), sendo considerado um fator de justiça social "ser dada a oportunidade a todos os cidadãos, e, em particular, aos menos escolarizados e aos ativos empregados e desempregados, de verem reconhecidas e certificadas as competências e conhecimentos que, nos mais variados contextos, foram adquirindo ao longo do seu percurso de vida" (Anefa, 2001b, p. 21).

Toda a criação do Sistema RVCC português regeu-se pelo princípio de que "é possível e necessário valorizar a experiência e as capacidades profissionais, além de pessoais e cívicas, dos adultos para melhorar também o seu nível educacional" (Silva, 2002, p. 73). Neste período fértil de criação dos CRVCC a prioridade foi assegurar o desenvolvimento do essencial dos processos metodológicos inerentes ao Sistema RVCC, ou seja: quer as bases do modelo de organização e intervenção inerente ao processo RVCC; quer os materiais específicos de apoio ao desenvolvimento estrutural e organizacional das práticas (foi elaborado um kit para o processo RVCC); quer dos diversos instrumentos diretos de apoio para os profissionais de RVCC e para os adultos em processo; quer de dispositivos indiretos de apoio para uma documentação técnica/pedagógica adequada a todos os intervenientes no processo de RVCC; quer da compilação e divulgação de materiais de suporte teórico ao processo de balanço de competências e à construção do Dossier Pessoal (Portefólio) dos adultos.

Dado o peso do reconhecimento de adquiridos experienciais na nova política público do sector, é importante destacar que o modelo adotado em Portugal para o Processo de RVCC pressupôs, desde a sua criação até ao momento presente, três eixos estruturantes de atuação e que são sequencialmente os seguintes: o eixo de reconhecimento de competências-chave; o eixo da sua validação; e o eixo da sua certificação. Assim, o eixo de reconhecimento de competênciaschave tem sido entendido no contexto nacional como o "processo de identificação pessoal das competências previamente adquiridas no qual se procura proporcionar ao adulto ocasiões de reflexão e avaliação da sua experiência de vida, levando-o ao reconhecimento das suas competências e promovendo a construção de projetos pessoais e profissionais significativos" (Anefa, 2002h, p. 15). Na medida em que o reconhecimento "é promovido numa lógica formativa, de incremento da motivação para aprender" (Conselho Nacional de Educação, 2002, p. 70), parte-se do pressuposto basilar de que o mesmo "constitui um passo extremamente importante na criação da identidade pessoal e social, no desenvolvimento da autoestima e da confiança do indivíduo para progredir em aprendizagem e no desenvolvimento de competências" (id., ibid.). Em termos processuais estipula-se que o reconhecimento de competências "constitui o conjunto das atividades, assentes numa lógica de balanço de competências e histórias de vida, 
no qual se promovem ocasiões de identificação e avaliação de competências, utilizando, para o efeito, um conjunto diversificado de meios" (Anefa, 2002h, p. 15), sendo, pois, no decorrer das diversas fases e atividades concretas que integram este eixo de intervenção que, como sublinham Correia e Cabete, "o adulto deverá construir, com o apoio do profissional de RVCC e dos formadores das quatro áreas de competências-chave, o seu dossier pessoal, documento onde se encontram todas as evidências documentais das competências de que o adulto é portador" (Correia \& Cabete, 2002, p. 49).

Na sequência deste processo de reconhecimento virá então o segundo eixo estruturante de atuação nos CRVCC, o eixo de validação de competências-chave, concebido como o "ato formal realizado por uma entidade devidamente acreditada que visa a atribuição de uma certificação com equivalência escolar" (Anefa, 2002h, p. 15), isto é, "representa o conjunto de práticas conducentes à atribuição de estatuto oficial e institucional às competências do indivíduo" (Conselho Nacional de Educação, 2002, p. 71). Processualmente a validação de competências fez-se até 2012, perante a apresentação oral do dossier pessoal a um júri de validação, que contava com a presença de um avaliador externo ao Centro, cuja missão, como referem Correia e Cabete, "consiste em analisar e avaliar o dossier pessoal apresentado pelo adulto, interpretando a correlação entre todas as evidências aí documentadas e o referencial de competências-chave" (Correia \& Cabete, 2002, p. 50).

Finalmente, a conclusão do processo de RVCC, tal como foi criado em Portugal, envolve o último dos eixos estruturantes referente à certificação das competências-chave. Este eixo foi entendido como a "confirmação oficial das competências adquiridas através da formação e/ou da experiência" (Anefa, 2002h, p. 16), e envolve, em termos processuais a "oficialização da validação das competências através do registo na Carteira Pessoal de Competências-chave e, sempre que for caso disso, por decisão do Júri de validação, haverá lugar à emissão de Certificados de nível Básico 3, 2 ou 1, equivalentes, para todos os efeitos legais, aos 3ㅇ, 2ㅇ ou 1은 Ciclos do Ensino Básico" (id., ibid.), sendo a certificação, propriamente dita, "proporcionada por via das Instituições formais do sistema educativo" (Conselho Nacional de Educação, 2002, p. 71). Quando todo o processo de RVCC se encontra concluído nestas três componentes sequenciais de ação, os produtos finais que ficavam na posse do adulto-educando, que percorreu este caminho num determinado CRVCC da Rede nacional, eram: o Dossier Pessoal ou Portfólio; a Carteira Pessoal de Competências-chave, e o Certificado.

No fundo, todo este processo inerente ao modo de implementação desta nova modalidade educacional para adultos pouco escolarizados, tal como foi introduzida e operacionalizada em Portugal, sobretudo no curto contexto institucional da ANEFA, teve como finalidade, de acordo com Ana Luísa Pires "promover a visibilidade destas aprendizagens informais, experienciais, e atribuir-lhes um 'valor de uso', tanto na esfera educativa como social e profissional" (Pires, 2005, p. 3). Trata-se, com efeito, de fazer assentar por princípio todo o processo de RVCC num axioma basilar da esfera tradicional da educação de adultos, o de que todos os adultos são portadores de um conjunto amplo, e frequentemente invisibilizado, de competências e saberes que adquiriram de múltiplas formas (Pineau, Lietard \& Chaput, 1997; Monteagudo, 2012; Simão, 2016).

Ora, o modo como os Profissionais de RVCC encaravam a sua função esteve profundamente âncorado nesta lógica pedagógica, e assentava em alguns momentos estruturantes, designadamente: o atendimento, a informação e o aconselhamento que se 
concebem logo à entrada do processo; seguidos da identificação de competências; e possivelmente por formações complementares; em cujo decurso são oferecidas informação e aconselhamento; até á validação e certificação. Aqui, parecem-nos ilustrativos estes testemunhos de profissionais de RVCC, recolhidos entre 2005 e 2004: ...compete-me levar o adulto a consciencializar-se da importância de todos os conhecimentos
que possui e seu respetivo valor (...) tenho que assumir um papel de facilitador de ajuda na
(re)descoberta das suas competências, o que, por vezes, se torna um processo difícil, na medida
em que a escolha é do adulto, é ele que tem nas suas "mãos" as suas competências. A minha
missão é motivá-lo, esclarecer as suas dúvidas, definir objetivos, entendê-lo, criar "à vontade" e
segurança, respeitá-lo, escutá-lo ativamente, aproximar-me do seu território, tendo o cuidado
de não interferir no seu espaço e evitando ao máximo que se sinta numa posição de
desconfiança e de inferioridade [RE (S) 2 ].

\begin{abstract}
...ao longo do meu trajeto de profissional de RVCC, procurei sempre estar atenta à minha prática e aos resultados que daí advinham, os quais foram sendo manifestados sobretudo pelos próprios adultos. Estou a falar, por exemplo, do tipo de linguagem que utilizava, o qual era demasiado académico e desajustado à realidade com que me deparava (adultos com baixos níveis de escolaridade). Este foi um dos aspetos que fui alterando ao longo da minha prática como profissional, tendo sempre em atenção as necessidades e motivações individuais dos adultos [RE (S) 1].
\end{abstract}

Concomitantemente e como resultado do facto, que já referimos, de esta oferta ter sido inscrita numa linha de enfrentamento do problema da subcertificação, verificou-se nos discursos públicos o reconhecimento do potencial do processo RVCC para a "construção de oportunidades e percursos de formação congruentes com os trajetos e as aquisições passadas dos formandos" (Silva, 2002, p. 142), a par da necessidade de se evitar que esta oferta se transformasse numa "atribuição administrativa de títulos escolares" (Silva, 2002, p. 142) motivada pela definição de metas físicas, neste período ainda confortáveis, que cada CRVCC teria de cumprir, em termos de certificação, para tornar este investimento eficaz no objetivo de contribuir para "recuperar, tão depressa quanto possível, o atraso acumulado" (Silva, 2002, p. 141).

Ora, após a extinção da ANEFA e a criação (Decreto - Lei n. 208/2002, DR 240, Série I-A, de 17 de Outubro) da Direção Geral de Formação Vocacional (DGFV), nasceria, neste âmbito, um modelo de gestão e avaliação de resultados imposto centralmente e destinado a ser operacionalizado perifericamente nas suas linhas mestras, com metas demasiado elevadas a cumprir e do qual se fez depender diretamente a aprovação de financiamento, resultando num acréscimo substancial de trabalho burocrático, como revelam testemunhos recolhidos na época, como por exemplo este:

...na prática, enquanto profissional de RVC, desenvolvo tarefas de natureza administrativa e
educativa. Entre as tarefas administrativas destaco a elaboração de atas e de fichas de avaliação
de desempenho, a realização do cronograma das sessões de trabalho com os adultos, o
preenchimento de documentos vários alusivos ao processo de cada adulto (contrato, carteira
pessoal de competências-chave, termos de posse, pedido de validação, diploma, entre outros),
os sumários das sessões, o estabelecimento de contactos, a participação nas reuniões da 
equipa, a planificação das sessões individuais e de grupo, e a colaboração com os outros profissionais do Centro RVCC, nomeadamente no que se refere à produção de relatórios, de artigos, entre outros trabalhos solicitados à equipa [RE (S) 1]

Noutra direção, também Fernanda Marques apontou duas variáveis que traduziam, à época, os problemas principais vividos pelos CRVCC desde que passaram a ser tutelados pela DGFV, nomeadamente: i) a variável do subfinanciamento; e ii) a variável que se prende com "a ausência de acompanhamento aos Centros por parte da tutela, o que se verifica desde 2003, e que tem como consequência podermos hoje afirmar que o sistema se encontra a funcionar em 'roda livre', sem qualquer controlo de qualidade de desempenhos e práticas" (Marques, 2007, p. 179). Também recolhemos inúmeros testemunhos que abordavam este problema, tal como este:

\footnotetext{
...em relação à DGFV há uma falta de acompanhamento e apoio aos Centros de RVCC (...) há mesmo uma falta de reconhecimento em relação ao nosso trabalho, muitas vezes, ou sempre, só reconhece as metas físicas, algo que na sua opinião reflete o bom ou mau desempenho do Centro. No ano de 2004, por exemplo, não houve acompanhamento ao nosso Centro, os encontros e as formações promovidas até hoje são "ocas" no seu conteúdo, e quando se levantam problemas de funcionamento, ou outros, não têm espaço para discussão [RE (A) 1]
}

Ora, as dificuldades sentidas no terreno por estas imposições ao Sistema EFA advindas da lógica de governação operacionalizada pela DGFV alertavam já os atores educacionais para a necessidade de encetar uma vigilância crítica para evitar que as novas ofertas de EFA se compartimentalizem tornando-se meros dispositivos paliativos, que a ser assim, não serviriam o projeto de emancipação pessoal e social dos cidadãos em geral e dos mais desfavorecidos em particular contido na visão com que o Programa de Ação s@ber +, enquanto política pública, continha. O risco era o de que as novas práticas de reconhecimento, validação e certificação de competências se transformassem em meros mecanismos renovados de confirmação das desigualdades sociais, e de eventuais percursos familiares de exclusão social e educacional, isto se o RVCC tende-se a ser usado para uma mera produção rápida de certificados escolares destinados aos adultos pouco escolarizados (Barros, 2009b; 2014; 2016).

\section{UMA POLÍTICA PÚBLICA VOCACIONADA PARA AS ESTATÍSTICAS: O IMPACTO DA UE NA INICIATIVA NOVA OPORTUNIDADES (2006-2012)}

A União Europeia (UE) como instância supranacional conseguiria transformar, através do Processo do Luxemburgo, aquilo que eram, na essência, políticas educativas nacionais para o sector da educação de adultos, mesmo que mitigadas, num mero capítulo da gestão global de recursos humanos, onde as novas políticas de EFA passam a ser consideradas. Com efeito o Espaço Europeu de Educação e Formação que nasceu, na viragem do século, de um conjunto articulado de iniciativas estreitamente articuladas, fomentou uma nova fase no processo de europeização das políticas educativas e de formação que acarretaria um profundo impacto para o sector educacional destinado aos adultos, desde logo visível, no caso português, na lógica de programa da Iniciativa Novas Oportunidades - INO (2006-2012). 
Ora, a INO pode ser interpretada como um instrumento de síntese da influência da agenda supranacional, cuja estratégia assentou em dois pilares fundamentais, por um lado, na ideia de dar oportunidades novas aos jovens através do incremento de cursos técnicos e profissionais e, por outro lado, na ideia de dar uma nova oportunidade aos adultos ativos através do aumento dos Cursos EFA e dos Processos de RVCC. Para ambos os eixos foram anunciadas, em dezembro de 2005, metas concretas a atingir até 2010, pretendendo-se atingir, no primeiro caso, a certificação-qualificação de cerca de 650000 jovens, e no segundo caso, a certificaçãoqualificação de cerca de 1000000 de adultos ativos (mais especificamente de 350000 por via dos Cursos EFA e os restantes 650000 por via do Processo RVCC).

De entre as doze medidas da INO, no eixo que se refere aos adultos ativos, destacamos a anunciada reconversão do Ensino Recorrente de Adultos (ERA) em Cursos EFA, bem como a pretensão de expandir significativamente a oferta deste sector a nível territorial, neste caso quer a oferta de Cursos EFA quer a oferta de CRVCC, aumentando também para o 12 ano (nível secundário) o nível de formação e certificação obtido por estas vias (ampliando, para tal, o respetivo Referencial de Competências-chave ${ }^{5}$, que até então estava orientado, como vimos, apenas para a escolaridade básica).

Não estando em causa o potencial do reconhecimento, validação, e mesmo certificação, dos adquiridos experienciais da população adulta, foram diversos os estudos que alertaram para um "pensamento 'mágico' ou administrativo que, por vezes, lhe surge associado" (Rodrigues \& Nóvoa, 2005, p. 11), lembrando que se impunha quebrar com a lógica paliativa com que as ofertas de EFA passaram a ser concebidas, desde então, no contexto português "como se a menção 'ao longo da vida' nos dispensasse de uma adequada formação de base. Como se o 'reconhecimento dos adquiridos' pudesse assentar numa lógica administrativa, de uma 'certificação formal', sem uma verdadeira implicação da pessoa num processo de reflexão, de aprendizagem pessoal e de desenvolvimento profissional" (id., ibid.: 12). Estes sinais de alerta permitiram questionar se o tipo de oferta pública de EFA serviria efetivamente a população portuguesa, ou se estaria inscrito na agenda das políticas educacionais, não para criar oportunidades significativas para a transformação e melhoria da vida dos coletivos populacionais, mas, apenas, como um expediente político de adequação nacional a um panorama internacional, isto no âmbito do novo paradigma das políticas para as estatísticas, para o qual neste sector o PIAAC (Programme for International Assessment of Adult Competencies) promovido pela Organização para a Cooperação e Desenvolvimento Económico (OCDE), tem vindo a dar um contributo assinalável (Evans, Close \& Maguire, 2010).

Se atendermos às especificidades da formação social portuguesa e da situação educacional da sua população adulta, então não se poderá ignorar, como sublinha Licínio Lima, que "para além de eventuais novas oportunidades em construção, talvez um dos problemas do século XX tenha sido (e esteja a ser) o não cumprimento das velhas oportunidades, das velhas promessas da modernidade, em termos de democratização, acesso à educação, intervenção social" (Lima, 1998, p. 19), sendo significativo em Portugal o facto da história do campo da

\footnotetext{
${ }^{5}$ No Referencial de Competências-chave do secundário, as áreas são: Cidadania e Profissionalidade (CP), Cultura, Língua e Comunicação (CLC) e Sociedade, Tecnologia e Ciência (STC). Ver: DGFV (2006). Referencial de Competências-chave para a Educação e Formação de Adultos (nível secundário). Lisboa: ME/DGFV. Disponível em: http://www.anqep.gov.pt/default.aspx
} 
educação de adultos mostrar que "muitas velhas oportunidades persistem como novíssimas oportunidades para uma boa parte da população portuguesa" (id., ibid.: 20).

Ora, se o Programa s@ber + (1999-2006) ampliou e diversificou a oferta educacional pública disponível para os adultos portugueses já o Programa INO (2006-2012) operou uma massificação (polémica em dispositivos de reconhecimento de adquiridos experienciais) que alargou exponencialmente a rede de Centros em funcionamento no território nacional (rebatizados como Centros Novas Oportunidades, CNO) e estipulou metas de resultados (outputs) avassaladores para os atores envolvidos, expressando novas contradições e tensões nos mandatos atribuídos à educação de adultos portuguesa e igualmente patente na mescla de elementos críticos e tecnocráticos presentes nos normativos do sector e nos discursos políticos associados (Guimarães \& Antunes, 2014). Com efeito, a INO desde logo apontou metas ambiciosas, quer para a criação de Centros, quer para o número de certificados. De acordo com dados fornecidos pela INO no Sistema de Informação e Gestāo da Oferta Educativa e Formativa (plataforma SIGO), referentes a dezembro de 2007, o total de adultos certificados que entre 2001 até 2005 havia sido de 59,040 (repartido entre os processos de RVCC num total de 44.253 e os Cursos EFA num total de 14.787) disparou para um total de 83.970, entre os anos de 2006 e 2007 (os processos de RVCC obtiveram um total de 76.922 e os Cursos EFA um total de 7.048).

O novo ciclo de governação educacional iniciado em 2005 (balizado, primeiro, pela Agenda/Estratégia de Lisboa, nascida no Conselho Europeu da primavera de 2000, e posteriormente, pelo seu relançamento reforçado no Conselho Europeu da primavera de 2005), acentuou a emergência em Portugal das políticas de racionalização, típicas do padrão de governação educacional prevalecente a nível supranacional. Ora, trata-se de um padrão de tipo tendencialmente neoliberal, assente na ideia da responsabilização individual pela empregabilidade através de mais educação e formação, de preferência ao longo de toda a vida, e em todos os lugares da vida, colonizando-se assim pela Aprendizagem ao Longo da Vida (ALV) todas as intermediações não-mercantis, anteriormente protegidas pelo Estrado Providência.

É, pois, cada vez mais visível neste cenário nacional de políticas de EFA que os novos instrumentos comuns de governação para o Espaço Europeu de Educação e Formação, foram bem-sucedidos a criar e potenciar uma nova ordem educacional (Field, 2002), caraterizada pela eficiência da 'nova administração pública', que em pouco tempo, certificou, de facto, um número significativo de adultos ao nível da escolaridade básica e secundaria. Foi, portanto, seguindo esta lógica de eficiência, que em 2006, o Despacho № 15 187, de 14 de julho determinava a abertura de CRVCC nas escolas, desde então rebatizados como Centros Novas oportunidades (CNO), apontando as habilitações necessárias aos professores/formadores das áreas do Referencial de Competências-chave e atribuindo créditos horários às escolas com ofertas para adultos. São ainda reiteradas as preocupações com a falta de certificação da população portuguesa, apontando-se a necessidade de colmatar essas lacunas através da criação de mais CNOs, porém aproveitando agora a própria rede escolar já existente.

A este significativo alargamento da rede de CNOs acrescentou-se, a partir de 2007, à lógica dos processos (ver anexo 1) a possibilidade de conclusão do ensino secundário (doze anos de escolaridade), também por via do reconhecimento de adquiridos experienciais (até aqui dirigido apenas à conclusão da escolaridade básica). O Despacho no 11 203/2007, de 8 de Junho e a Portaria no 370/2008, de 21 de maio determinaram os moldes em que se faria a expansão de 
funções nos CNO e qual a nova composição da equipa: um diretor, um coordenador, um técnico de diagnóstico e encaminhamento, formadores, profissionais de RVC e técnicos administrativos.

Nesta altura foi também criada a Agência Nacional para a Qualificação (ANQ) que veio substituir a DGFV (Decreto-lei n.ㅇ 213/2006, de 27 de Outubro). Neste âmbito os CNOs tinham como missão assegurar a educação e formação de jovens e adultos, prometendo resultados rápidos e eficazes, no sentido da melhoria das qualificações, as quais eram inferiores às da média europeia (Távora, Vaz \& Coimbra, p. 2013). Os CNOs estiveram associados a uma enorme divulgação, marketing e publicitação sem precedentes em Portugal, que, em definitivo, colocou a EFA na praça pública e popularizou o sector.

Porém, e não obstante a forte visibilidade pública que o campo da EFA adquiriu, totalmente inédito na sua história nacional, e o aclamado sucesso medido pelo elevado número de centros e de candidatos certificados, esta medida foi alvo de diversas críticas, sendo a mais recorrente a que se prende com a elevada pressão que era exercida sobre os CNOs no sentido da obtenção das metas (Távora, Vaz \& Coimbra, 2013; Martins, 2014). O que, aliás, suscitou avisos originados em diversos quadrantes da sociedade portuguesa, dos quais destacamos o quadrante da academia, onde, entre outros exemplos, António Nóvoa e Rui Canário alertavam respetivamente, quer para a ideia de que "olhar para os RVCC como no passado se olhou para as 'campanhas de alfabetização', vendo-os como a solução mágica para resolver o 'atraso educacional português', seria a mais perigosa das ilusões" (Nóvoa, 2007, p. 12); quer de que "a justificação do programa retoma os habituais e 'velhos' clichés sobre a relação direta e linear entre o investimento na qualificação dos recursos humanos e o 'crescimento económico', o 'desenvolvimento', a 'superação do atraso', o 'emprego', a 'produtividade', a 'competitividade' e a 'coesão social'. Ora, não ficará mal reconhecer que esta relação direta não existe" (Canário, 2007, p. 167).

Várias foram, portanto, as evidências que demonstraram que a INO representou um exemplo nacional de uma política para as estatísticas, baseada no que Brown diz ser uma "retórica inclusiva para uma realidade exclusiva" (Brown, 2000, p. 38), e em que se disseminou um discurso das oportunidades e da empregabilidade que contribuiu, no nosso entender, em larga medida para distribuir ilusões, dada a sua ocorrência num contexto de crescente crise estrutural motivada por capitalismo globalizado cada vez mais predatório e implácavel (Comparato, 2011).

\section{A HIBERNAÇÃO DAS POLÍTICAS SOCIAIS PÚBLICAS EM CONTEXTO DE AUSTERIDADE ECONÓMICA - IMPACTOS NACIONAIS NA EFA (2013-2015) DA NOVA GOVERNAÇÃO GLOBAL}

No contexto da mais recente crise economica e financeira internacional, o 18 으 Governo Constitucional de Portugal (2009-2011, Partido Socialista) pediu uma intervenção conjunta do Fundo Monetário Internacional (FMI), da Comissão Europeia (CE) e do Banco Central Europeu (BCE). Desta parceria resultou um Memorando de Entendimento (Plano da Troika), assinado em 2011, que veio a implicar a adoção de um conjunto de medidas assentes numa política economico-financeira de austeridade (Schui, 2015) conducente a reformas estruturais cuja carateristica principal se vem pautando por um duplo défice: i) um défice democrático na tomada 
de decisão, crescentemente circunscrita a uma elite de tecnocratas, e ii) um défice de respostas do sistema político aos problemas sociais, que se agravam visivelmente.

Ora, de acordo com Navarro (2015), muitas das medidas neoliberais que se estão a tomar, neste periodo de grande recessão, para melhorar o sistema financeiro, estão a piorar, em vez de melhorar, a situação económica, aumentando o empobrecimento geral e o descontentamento popular na Europa, ao mesmo tempo em que o establishment da UE e do Eurogrupo permanece intocado. Com efeito, este fenomeno tem sido referido como uma estranha sobrevivência do neoliberalismo (Crouch, 2011), que não obstante o aumento exponencial do mal-estar geral permanece como uma cartilha a seguir, na qual se advoga pela privatização dos domínios públicos, pela desregulação da economia, pela flexibilização do trabalho, pela eficiência e produtividade, pelas instituições do livre mercado e livre comércio, pelos direitos da propriedade privada, pela redução das cargas fiscais, pela diminuição do tamanho do Estado, pela redução na despesa da segurança social, pela responsabilização de cada indivíduo pela sua empregabilidade e qualificações, e todo um rol de pressupostos que caraterizam a paisagem da hegemonia ideológica do neoliberalismo (Harvey, 2007).

Ora, a sua intensificação na Europa ficou também associada às alterações governativas em Portugal que conduziram ao advento do 19 Governo Constitucional (2011-2015, Partido Social Democrata em coligação com a direita) que extrapolaria o próprio Memorando de Entendimento, impondo severas políticas de austeridade conducentes, neste âmbito educacional que estamos a analisar, diretamente à extinção da rede de CNOs. Surgem, então, novos centros designados de Centros para a Qualificação e o Ensino Profissional (CQEP), porém em muito menor número que os anteriores e, como seria de esperar face à adoção das políticas neoliberais, sem qualquer financiamento.

Assim, sendo a nova legislação afeta à regulação da organização dos novos CQEP (Portaria no 135-A/2013 de 28 de março) introduziu, desde logo, a redução do número de elementos constitutivos das equipas, face ao modelo anterior dos CNOs. Designadamente, a figura do diretor (presente nos CNOs) foi extinta, o coordenador pedagógico (dos CNOs) deu lugar à figura de coordenador (nos CQEPs), os profissionais de RVC (nos CNOs) passaram a ser técnicos de Orientação, Reconhecimento, Validação e Certificação - ORVC (nos CQEPs), os formadores embora visto como necessários passaram agora a ser em menor número, de acordo com as disponibilidades das escolas dado que os centros deixaram de ter financiamento próprio, acontecendo frequentemente que os próprios Técnicos de ORVC desempenharam o papel de formadores e vice-versa. Ora, quando os centros estavam instalados em escolas, no modelo CNOs, a disponibilidade dos professores destacados era total na maior parte dos casos, nos CQEPs, cada professor, independentemente do cargo ocupado no centro, passou a dispor de uma carga horária limitada, sendo o seu restante horário constituído por turmas do ensino regular em que deve lecionar. Emerge, desta forma, uma nova relação entre o CQEP e a escola, em que o centro ficaria claramente a perder, como referem estes testemunhos de técnicas, 
E há outra desvantagem... é que, se a pessoa estiver única e exclusivamente como formadora de um Centro, terá mais disponibilidade, pronto, estará mais concentrada apenas no Centro. Aqui nós acabamos por ter que nos dividir... (E1)

Não obstante, dos anteriores CNOs os novos CQEPs herdaram os passos necessários para acompanhar os candidatos (ver anexo 1), desde o acolhimento, o diagnóstico, a informação e orientação e o encaminhamento, não herdando porém a mesma dimensão da equipa o que nas palavras de uma técnica basicamente significou:

Como tínhamos pessoal limitado, como técnicas fazíamos tudo... desde o acolhimento do adulto, a sua inscrição e depois as diferentes fases. A parte de informação, de diagnóstico, até ao encaminhamento. Sempre, fazíamos tudo. Inclusivamente, até fazíamos a seguir, depois os processos RVCC, fazíamos também a formação. Nós fizemos tudo (E2)

As ofertas chave disponíveis não sofreram alteração, mantendo-se tanto os Cursos EFA, nas vertentes escolar e de dupla certificação, como o processo RVCC. Porém, neste quadro a grande inovação a merecer destaque que foi introduzida pela nova agenda política associada aos CQEPs manifestou-se através da inclusão de uma prova, no caso dos processos RVCC, com o valor de $60 \%$ da totalidade do processo, nas modalidades escrita e oral. Esta caraterística, nova em Portugal no âmbito do processo de reconhecimento de adquiridos experienciais, apareceu justificada no discurso público como uma pretensão de atribuir mais rigor ao processo, que sofreu algum descrédito na fase de expansionismo acelerado da rede de CNOs. Como recorda uma técnica,

A prova foi importante porque o processo estava um pouco descredibilizado, digamos que o processo... havia muita gente a por dúvidas... (E2)

Desde o início que a questão da elaboração da prova, da responsabilidade das equipas dos CQEPs suscitou debate, já que as provas de cada área de competência tinham de contemplar todos os temas (no caso do RVCC básico) ou todos os domínios de referência (no caso do RVCC de nível secundário), o que originaria uma prova demasiado longa. A resposta encontrada para este problema, de resto inusitado no âmbito dos princípios pedagógicos inerentes à educação de adultos (Lindeman, 1926; Freire, 1968; Gelpi, 1994; Malglaive, 1995, Milana, 2009) por parte de alguns centros, passou pela construção de provas com questões de desenvolvimento intercaladas com outras de resposta curta ou de escolha múltipla. Nas questões de desenvolvimento eram oferecidas em geral várias possibilidades, dando abertura, e incentivando aos candidatos a integração das suas experiências de vida nas temáticas dos diversos núcleos geradores das áreas de competência-chave.

Em suma, o que se destaca durante este período basicamente é uma ação política nacional impositiva, com uma aliança supranacional assumida, através da qual se minimizou a dimensão da rede de centros anteriormente criada, se reduziu substancialmente a dimensão das equipas, se retirou $60 \%$ de valor ao portfólio construído com base em metodologias de 
proximidade como as abordagens biográficas e o balanço de competências, e se abandonou o financiamento aos centros. Ou seja, dito por outras palavras, sob uma ação política justificada por um discurso público de crise e austeridade, de legitimação externa, a educação de adultos em Portugal desapareceu da agenda política.

\section{A AGENDA GLOBALMENTE ESTRUTURADA E AS RESISTÊNCIAS NACIONAIS - OBSERVANDO AS DINÂMICAS DO PROGRAMA QUALIFICA (2017)}

Neste momento da nossa reflexão advogamos que o uso do conceito de governação a várias escalas (pluriescalar) possibilita captar as lógicas ambivalentes com que se jogam hoje interesses múltiplos e transnacionais na decisão política em educação. Trata-se de uma categoria teórica para apreender as complexas dimensões da governação em contexto de globalização político-económica neoliberal, particularmente em contexto europeu e desde a Agenda de Lisboa, privilegiando uma abordagem sociológica que entrecruza os diversos níveis analíticos (mega, macro, meso e micro). De acordo com Roger Dale a governação da educação é na atualidade um assunto pluriescalar quer porque "potencialmente tem lugar em várias escalas, e não apenas ao nível do Estado-nação" (Dale, 2005, p. 63), quer porque "não é internacional, com as suas implicações de múltiplas localizações (tipicamente Estados-nação) na mesma escala" (id., ibid., p. 63). Nas palavras deste autor,

O que estamos agora a testemunhar é não apenas um desvio do Estado, que assume a responsabilidade direta por todas as atividades, e da própria regra para o Estado que determina quem assumirá a responsabilidade por elas, mas que as combinações à escala nacional de atividades [financiamento, posse, fornecimento e regulação] e instituições [Estado, Mercado, Comunidade e Família] de governação têm de ser aumentadas pelo reconhecimento de que, potencialmente, qualquer uma ou todas estas atividades podem também ser geridas a uma escala diferente [supranacional, nacional e subnacional] (id., ibid., p.63).

Com esta ordem de ideias, podemos pensar melhor nas várias escalas interrelacionadas de governação da nova EFA (supranacional, nacional e subnacional), que no nosso entender, ganham complexidade com as alterações governativas de finais de 2015, em que foram criados, pelo 20 Governo Constitucional (Partido Socialista em coligação com a esquerda), os Centros Qualifica (CQ) que passaram muito recentemente a substituir os anteriores CQEPs (Portaria 232/2016 de 29 de agosto, e Despacho 1971 de 8/3/2017). Ora, entre outros aspetos o Governo em funções herdou a crise de legitimidade das severas medidas neoliberais de ajustamento da sociedade e do Estado quer às demandas supranacionais quer aos agentes financeiros nacionais, que têm vindo a pressionar visivelmente a macroestrutura no sentido da privatização dos lucros e da socialização dos prejuízos. Não sendo expectável que a ação governativa fosse suspender a política de austeridade, verificou-se, no entanto, um reconhecimento subtil no novo discurso público de que há alternativas contrárias ao empobrecimento dos Estados e das populações e que se pode dar um uso menos ortodoxo à margem (estreita) de manobra que uma certa soberania nacional ainda permite.

Assim, e em contra-ciclo com as medidas anteriores, as principais inovações introduzidas nos novos Centros Qualifica foram, por um lado, o alargamento das equipas, com a contratação 
de dois Técnicos de ORVC, autorizada em outubro de 2016, os quais, não sendo professores, dedicam as suas 35 horas de trabalho semanais ao centro, possibilitando assim outra dinâmica nos atendimentos, encaminhamentos e processos RVCC, bem como um maior avanço em todos os aspetos burocráticos; e por outro lado, as várias fases do processo, nomeadamente: o acolhimento, o disgnóstico, a informação e orientação e o encaminhamento passaram a dispor de uma maior quantidade de tempo, contabilizado no âmbito do número de registos autorizados de sessões por etapa na plataforma SIGO, sendo agora as equipas, a partir de março de 2017, compostas do seguinte modo: um coordenador, dois Técnicos de ORVC e vários formadores, todos professores e com parte dos seus horários preenchidos com turmas.

No quadro da nova política pública para o sector da EFA, agora designada de Programa Qualifica, verifica-se que "o Governo estabeleceu como prioridade política de âmbito nacional a revitalização da educação e formação de adultos, enquanto pilar central do sistema de qualificações, assegurando a continuidade das políticas de aprendizagem ao longo da vida e a permanente melhoria da qualidade dos processos e resultados de aprendizagem" ( $P Q, \mathrm{~s} / \mathrm{p}$ ). Nesse sentido apostou-se na criação de dispositivos de apoio novos, que se enquadram em orientações muito práticas quer para o processo RVCC, quer para os Cursos EFA, e que aparecem propostos em dois documentos: i) o Guia Metodológico; e ii) a Orientação Metodológica N.o 1 (Anqep, 2017a; 2017b). Criou-se também o Passaporte Qualifica, documento a que se acede através do SIGO, onde serão registadas as formações validadas dos candidatos e que pretende possibilitar um melhor cruzamento de dados.

Outra alteração significativa face ao modelo anterior (o modelo dos CQEP) surge no âmbito da prova, que deixando de ser escrita passa a ser uma apresentação oral perante um júri de certificação, no fundo retomou-se, no essencial, a lógica do júri de validação existente no período de vigência dos CRVCC. A Orientação Metodológica N.o 1 aponta três momentos nesse processo, designadamente: i) o da preparação para a prova, que poderá decorrer até 25 horas; ii) o momento do Júri de Certificação, que agora se designa como prova; e finalmente, iii) um terceiro momento a que chama avaliação e tomada de decisão. A importância da prova continua a ser significativa, sendo considerada como o remate final do trabalho do candidato, cuja preparação é agora bem mais acompanhada pela equipa, sobretudo pelos Técnicos de ORVC e pelos formadores. Efetivamente, neste particular as diferenças, face ao modelo anterior, são significativas dado que nem a prova tem avaliação quantitativa nem é escrita.

Há ainda a destacar o aspeto da formação complementar aos candidatos RVCC que nos CQEP podia atingir 25 horas e que se apresenta agora nos Centros Qualifica como um imperativo, sendo no mínimo de 50 horas. A questão é apresentada ao nível do Programa Qualifica como destinada a possibilitar a formação nas áreas em que o candidato apresente menos competências. Porém não é uma opção isenta de problemas, dado que, por um lado, representa um acréscimo de dificuldades na elaboração de grupos e horários para formação presencial, e por outro lado, há o paradoxo de os Centros Qualifica, que são parte da oferta pública nacional, continuarem a não ter financiamento enquanto os cursos, assegurados por entidades privadas sob a forma de protocolos, beneficiam de financiamento. São aspetos sublinhados, por exemplo nestes testemunhos que recolhemos,

Sim, duplicou. Sim, sim, sim. Pronto, torna-se complicado para algumas pessoas, porquê, porque pretendendo-se fazer sessões em grupo, hum... no Algarve e acho que em todo o lado, eu acho que nós temos o problema das pessoas, seguranças têm horários rotativos, supermercados, rotativos, hospitais, rotativos... portanto, é muito difícil arranjar horários em que as pessoas possam vir... (...) Mas há esse problema, há. Acho que são muitas horas... eu 
pessoalmente julgo que são muitas horas presenciais. Pronto, que deveria ser... há pessoas que podem necessitar dessas 50 horas de facto. Mas há outras que não necessitam... (E1)

O coordenador tem feito alguns protocolos (...) Têm é sempre muitas dificuldades em abrir os cursos. Que há falta de candidatos... por isso é que... por isso é que eles procuram os protocolos aqui junto do Centro, para garantir logo um número razoável de pessoas para abrir...mas eles têm financiamento, têm (E2)

Relativamente à permanência dos Centros Qualifica nas escolas, são sublinhadas as desvantagens já percecionadas no âmbito dos CQEPs, embora, ambivalentemente, nos contextos de práticas se admitam certas vantagens também, designadamente na recondução de jovens alunos da própria escola com insucesso para o centro, onde normalmente são encaminhados para as ofertas de cursos EFA de certificação escolar atualmente existentes. Trata-se de uma situação controversa dado que gera situações desiguais no acesso quando o objetivo é o prosseguimento de estudos ao nível superior. Neste particular os testemunhos seguintes são esclarecedores,

Hum... de facto, nós temos, por exemplo, uma das vias de conclusão do ensino secundário são os EFAs, que nós encaminhamos esses alunos para EFAs. E... e a maior parte desses alunos são alunos da escola, portanto... a primeira coisa é... é contactar aqui o Centro. E aliás, neste momento até praticamente já todos os professores conhecem e... da própria escola, e... e encaminham esses alunos para... para o Centro, porque sabem que aqui há uma forma de eles terminarem o ensino secundário... quando eles têm essa dificuldade (E2)

E os próprios cursos EFA começam também a criar alguma injustiça. Porque eu acho que... eles não foram criados para o fim com que estão a ser aproveitados atualmente, pelos jovens que não conseguem concluir o ensino secundário (...) inclusivamente a... a perspicácia dos nossos jovens já chega a um ponto de um jovem me ter anulado a matrícula este ano numa turma que eu tenho de $12^{\circ}$ ano, hum... o aluno tinha notas para passar, para concluir o 12 o ano, depois teria que fazer os exames, mas tinha notas positivas, e o aluno anulou a matrícula para entrar num curso EFA, para perder as notas... porque ele teria nota de 12 e a média não lhe chegava para entrar na universidade. Portanto, o aluno já utiliza... está a tentar utilizar o curso EFA, perder a nota e conseguir ter uma nota superior no exame da específica, para conseguir o acesso ao ensino superior, precisa de um 16... (...) entra só com a nota desse exame. Entra, entra... entra com o certificado do curso EFA, sem nota, e a nota que conta é a nota do exame que ele vai fazer (E1)

Por fim, é interessante notar que o processo de RVCC, em termos gerais, é percecionado nas comunidades de práticas como adequado aos adultos pouco escolarizados, o que não deixa de ser contraditório com os dados existentes no SIGO, que atestam uma taxa de desistência e abandono bastante significativa. Porém, o facto é também que a conjuntura criada por uma política educacional para este sector que se vem revelando manifestamente inconsistente, não contribuirá para motivar adultos pouco escolaizados com experiencias pouco positivas da escola para iniciarem e manterem processos de reconhecimento de adquiridos experienciais que correm riscos reais de serem abruptamente interrompidos, como sucedeu recentemente.

Se é certo que o cenário político nacional, no presente momento, comporta sinais de resistência e mudanças em prol dos direitos sociais, a dimensão dessas mudanças e a capacidade da sua manutenção no tempo estarão, porém, sob a nossa observação atenta. 


\section{NOTAS FINAIS}

O texto demonstra que as políticas portuguesas de EFA aparecem hoje imbricadas num novo contexto europeu de políticas coordenadas, configurando uma matriz de políticas pluriescalar cujas prioridades têm emanado, invariavelmente, da esfera económica.

O que está a acontecer com a emergência do Estado policentrado regulador de pendor neoliberal é um estreitamento radical dos pressupostos humanistas que desenhavam as políticas educacionais como um direito social para ser democraticamente negociado nos fóruns nacionais dos Estados-providência, como, em contra-hegemonia ainda se pode ler na Recomendação de 2015 da UNESCO sobre aprendizagem e educação de adultos, onde se afirma: "all Member States, according to their specific conditions, governing structures and constitutional provisions, should develop comprehensive, inclusive and integrated policies for adult learning and education in its various forms" (Unesco, 2016, p. 8).

Porém o que predomina hoje como corolário principal das políticas de austeridade, que o caso português ilustra, é "um estilo elitista de gestão pública" (Coraggio, 2000, p. 83) baseado numa "intelligentsia governamental" que faz acordos de cúpula com atores globais optando por realizar um "trabalho especial para legitimar ex post facto esses acordos" (id., ibid.). Ou seja, a nova política transeuropeia em que emergem novos atores, novas instituições e novos processos, envolve, preocupantemente, na contemporaneidade, como enfatiza Antunes, "formas acentuadas de défice democrático através das quais paulatinamente o campo de decisão política pública tem vindo a ser reconstruído" (Antunes, 2006, p. 87).

É, pois, neste cenário de fundo que nasceu todo um novo contexto de desenvolvimento das políticas de EFA, em que, significativamente, os atores de EFA nacionais, por relação aos atores globais, e os atores de EFA subnacionais, por relação aos atores nacionais, veem crescentemente reduzida a sua influência sociopolítica ao campo da mera execução das políticas, num processo que vem evoluindo para uma tendencial "exclusão dos protagonistas e dos processos eventualmente fraturantes (...) expediente [que] se revela inteiramente eficaz na eliminação dos conflitos de interesses e no silenciamento das divergências" (Antunes, 2007, p. 50).

Ora, a maior inovação que em Portugal foi introduzida em materia de EFA refere-se à incorporação no âmbito de todo o sistema educacional de oferta pública para adultos (e jovens) de uma lógica de valorização das aprendizagens experienciais, que fez emergir no cenário nacional o reconhecimento de adquiridos experienciais a partir de 2001. Em quinze anos de história, o RVCC português representa, não obstante as tensões e contradições cronologicamente percorridas neste texto, uma área de conhecimento e prática incontornável.

Assim sendo, ainda é cedo para avaliar se as medidas do Programa Qualifica irão representar ou não a inversão de um impasse político que efetivamente existiu entre 2013 e 2015 e que bloqueou o sistema, levantando barreiras à população adulta educacionalmente mais vulnerável do país.

Terminamos, assim, em aberto esta reflexão querendo saber, entre outros aspetos, que possibilidade há, hoje, no contexto português, de se concretizar uma nova oportunidade para a educação de adultos, de modo a se conseguir criar, através dela, uma oportunidade significativa de mudança em prol de uma humanidade mais humanizada, para nós e para as gerações vindouras que hão de sobreviver à ameaça do capitalismo neoliberal opressor. 


\section{REFERÊNCIAS}

ANEFA. (2001a). Plano de Atividades 2001. Lisboa: ANEFA.

ANEFA. (2001b). Relatório de atividades 2000. Lisboa: ANEFA.

ANEFA. (2002a). Plano de Atividades 2002. Lisboa: ANEFA.

ANEFA. (2002c). Cursos de educação e formação de adultos: Documento de trabalho. Lisboa: ANEFA.

ANEFA. (2002e). Relatório nacional: Cursos de educação e formação de adultos "Em observação" 2000/2001. Lisboa: ANEFA.

ANEFA. (2002h). Centros de Reconhecimento, Validação e Certificação de Competências - Roteiro Estruturante. Lisboa: ANEFA.

ANEFA. (2002i). Referencial de Competências-chave para a Educação e Formação de Adultos (nível básico). Lisboa: ANEFA. Disponível em: http://www.anqep.gov.pt/default.aspx

ANQEP. (2017a). Orientação ao Longo da Vida nos Centros Qualifica - Guia Metodológico. Lisboa: ANQEP.

ANQEP. (2017b). Reconhecimento, Validação e Certificação de Competências Escolares (RVCC Escolar) - Orientação Metodológica N.o 1. Lisboa: ANQEP.

Antunes, F. (2006). Governação e Espaço Europeu de Educação: Regulação da Educação e visões para o Projeto 'Europa'. Revista Crítica de Ciências Sociais, 75, 63-93.

Antunes, F. (2007). A Nova Ordem Educativa Mundial e a União Europeia: A Formação de Professores - dos Princípios Comuns ao Ângulo Português. Revista do Fórum Português de Administração Educacional, 46-64.

Azevedo, M. \& Tavares, M. (2015). Educação de jovens e adultos e educação profissional no Brasil: caminhos e descaminhos no contexto da diversidade, HOLOS, Ano 31, Vol. 4, 107118.

Barros, R. (2009a). Subsídios para a construção de um racional teórico para investigar os (novos) modos de governação e regulação das políticas educativas no sector da educação de adultos em Portugal. In H. Ferreira, C. Lima, F. Alves, G. Santos, \& S. Bergano (Orgs.), Atas do $X$ Congresso da Sociedade Portuguesa de Ciências da Educação (SPCE): Investigar, avaliar, descentralizar. Bragança: Instituto Politécnico de Bragança.

Barros, R. (2009b). Políticas para a educação de adultos em Portugal: A governação pluriescalar da "Nova Educação e Formação de Adultos» (1996-2006). Volume I e II. (Tese de doutoramento não publicada). Universidade do Minho, Braga.

Barros, R. (2013a). A Agência Nacional para a Educação e Formação de Adultos (ANEFA) - um marco na europeização da agenda pública do sector, Revista Portuguesa de Educação, 26 (1), 59-86.

Barros, R. (2013b). As políticas educativas para o sector da educação de adultos em Portugal: As novas instituições e processos educativos emergentes entre 1996-2006. Lisboa: Chiado Editora.

Barros, R. (2014). The Portuguese recognition of prior learning (RPL) policy agenda: Examining a volatile panacea by means of ethno-phenomenological interpretations. Encyclopaideia, Journal of Phenomenology and Education, XVIII(40), 53-68.

Barros, R. (2016). The Portuguese case of RPL new practices and new adult educators: Some tensions and ambivalences in the framework of new public policies. In P. Andersson; A. Fejes; F. Sandberg (Eds), Researching recognition of prior learning around the globe. (pp. 26-42). London: Routledge. 
Barros, R. \& Belando-Montoro, M. (2013). Europeização das Políticas de Educação de Adultos: Reflexões Teóricas a partir dos Casos de Espanha e Portugal, Education Policy Analysis Archives, Vol. 21, No. 71, pp. 1-28.

Benavente, A. \& Rosa, A. \& Costa, A. \& Ávila, P., (1995). A Literacia em Portugal - Resultados de uma Pesquisa Extensiva e Monográfica. Lisboa: Fundação Calouste Gulbenkian/Conselho Nacional de Educação.

Brown, U. (2000). Inclusive Rhetoric, Exclusive Reality. In Jane Thompson \& Mae Shaw \& Liam Bane (Ed.). Reclaiming Common Purpose (pp. 38-41). Nottingham: NIACE.

CONSELHO NACIONAL DE EDUCAÇÃO. (2002). Aprendizagem ao Longo da Vida (Parecer no 1/01, redigido por A. Rita Varela). In CNE, Pareceres e Recomendações, 2001 (pp. 15-136). Lisboa: CNE/ Ministério da Educação.

Correia, A. \& Cabete, D. (2002). O valor do que Aprendemos ao Longo da nossa Vida... e a Importância do Sistema Português de Reconhecimento, Validação e Certificação de Competências. In Isabel Melo e Silva, José Alberto Leitão e Maria Márcia Trigo (org.). Educação e Formação de Adultos - Factor de Desenvolvimento, Inovação $e$ Competitividade (pp. 45-53). Lisboa: ANEFA.

Canário, R. (2007). A Educação e o Movimento Popular do 25 de Abril. In Rui Canário (org.). Educação Popular \& Movimentos Sociais (pp. 11-36). Lisboa: Educa/Unidade de I\&D de Ciências da Educação.

Comparato, F. (2011). Capitalismo: civilização e poder, Estudos Avançados, 25 (72), 251-276.

Crouch, C. (2011). The Strange Non-death of Neoliberalism. Cambridge: Polity Press.

Dale, R. (2005). A Globalização e a Reavaliação da Governação Educacional. Um Caso de Ectopia Sociológica. In António Magalhães e Carlos Alberto Torres, Educação Crítica e Utopia. Perspetivas para o Século XXI (pp. 53-69). Porto: Edições Afrontamento.

Dale, R., \& Robertson, S., (2014) Global education policies, in N. Yeates (ed) Understanding global social policy. (pp. 209-235). Bristol: Policy Press.

DGFV. (2006). Referencial de Competências-chave para a Educação e Formação de Adultos (nível secundário). Lisboa: ME/DGFV. Disponível em: http://www.anqep.gov.pt/default.aspx

Evans, J. \& Close, S. \& Maguire, T. (2010). The new international adult numeracy survey: the design of PIAAC. In Griffiths, G. \& Kaye, D. (Editors), Numeracy Works for Life: Proceedings of the 16th International Conference of Adults Learning Mathematics - A Research Forum (pp. 273-285). UK: London Language \& Literacy Unit.

Field, J. (2002). Lifelong Learning and the New Educational Order. London: Trentham Books.

Freire, P. (1968). Educação como Prática da Liberdade. Rio de Janeiro: Paz e Terra.

Gelpi, E. (1994). Adult Education for Export. In Metka Svetina (ed.), Rethinking Adult Education for Development II (pp.79-86). Ljubljana: Slovene Adult Education Centre.

Guimarães, P. \& Antunes, F. (2014). An inconsistent policy: lifelong learning and adult education policy towards a competitive advantage. In: Gravani, M.; Zarifis, G. (Eds.). Challenging the 'European area of lifelong learning'. A critical response. Dordrecht: Springer, pp. 7586.

Harvey, D. (2007). Breve Historia del Neoliberalismo. Madrid: Akal.

INO. (2005). Iniciativa novas oportunidades. Consultado em http://212.55.143.51/documentos.aspx

Jessop, B. (1998). The rise of governance and the risks of failure: The case of economic development. International Science Journal, 155, 29-45. 
Lima, L. (1998). Políticas Educativas, Novas (e Velhas) Oportunidades. In A Educação na Viragem do Século XX - Atas das I Jornadas de Educação. Braga: Núcleo de Estudantes de Educação da Universidade do Minho.

Lindeman, E. C. (1926). The Meaning of Adult Education. New York: New Republic.

Malglaive, G. (1995). Ensinar Adultos. Porto: Porto Editora.

Marques, F. (2007). Centros RVCC: Análise da Situação e Propostas. In Conselho Nacional de Educação, Aprendizagem ao Longo da Vida no Debate Nacional de Educação (pp. 177184). Lisboa: CNE/ Ministério da Educação.

Martins, J. (2014). Das políticas às práticas de educação de adultos. Lisboa: Edições Colibri.

Melo, A. (2001). Uma Nova Vontade Política de Relançar a Educação e Formação de Adultos? In António Teodoro (org.). Educar, Promover, Emancipar - os contributos de Paulo Freire e Rui Grácio para uma Pedagogia Emancipatória (pp. 101-120). Lisboa: Edições Universitárias Lusófonas.

Melo, A. \& Queirós, A. \& Santos Silva, A. \& Salgado, L. \& Rothes, L. \& Ribeiro, M. (1998). Uma Aposta Educativa na Participação de Todos - Documento de Estratégia para o Desenvolvimento da Educação de Adultos. Lisboa: Ministério da Educação.

Melo, A., \& Matos, L. \& Silva, O. (2001). S@ber +: Programa para o Desenvolvimento e Expansão da Educação e Formação de Adultos, 1999-2006. Lisboa: ANEFA/GMEFA.

Milana, M. (2009). Opportunity structures for adult educators to acquire (pedagogical) qualifications in Denmark. Journal of Educational Sciences, XI (1(19)), 95-102.

Monteagudo, J. G. (2012). Ruralidades, cambio generacional y formación en las narrativas autobiográficas. In Souza, E. (Org.) Educacâo e Ruralidades: Memórias e Narrativas (Auto)Biográficas. (pp. 225 - 249 ). Bahía: EDUFBA.

Navarro, V. (2015). Ataque a la Democracia y al Bienestar. España: Anagrama.

Nóvoa, A. (2007). É Preciso Manter uma Vigilância Crítica sobre o Reconhecimento de Adquiridos - Entrevista a António Nóvoa. In Aprender ao Longo da Vida, 7, 10-18.

PACTO EDUCATIVO PARA O FUTURO. (1996). In António Teodoro (coord.). Pacto Educativo Aspirações e Controvérsias (pp. 90-96). Lisboa: Texto Editora.

Pineau, G. \& Lietard, B. \& Chaput, M. (Cood.). (1997). Reconnaître les acquis: Démarches d'exploration personnalisée. Paris: L'Harmattan.

Pires, A. L. (2005). O Reconhecimento e a Validação das Aprendizagens dos Adultos: Contributos para a Reflexão Educativa (policopiado).

PLANO NACIONAL DE EMPREGO. (1999). PNE 2000-2005. Lisboa: Conselho Permanente da Concertação Social.

Rodrigues, C. \& Nóvoa, A. (2005). Prefácio. In Rui Canário; Belmiro Cabrito (org.). Educação e Formação de Adultos - Mutações e Convergências, (pp. 7-14). Lisboa: EDUCA-Formação.

Schui, F. (2015). Austeridade: Breve História de um Grande Erro. Lisboa: Editorial Presença.

Silva, A. S. (2002). Por uma política de ideias em educação. Porto: Edições ASA.

Simão, A. (2016). Narrativas de formação: potenciar experiencias críticas e autorregulatórias. In Monteiro, F.; Nacarato, A.; Fontoura, H. Narrativas docentes, memórias e formação (pp. 69-82). Curitiba: Editora CRV.

Távora, A. \& Vaz, H. \& Coimbra, J. (2013). Educação e Formação de Adultos em Portugal: a história de uma alternância de políticas sem alternativa social. in N. Alves, C. Cavaco, P. Guimarães \& M. Marques (Eds.), Atas do VI Seminário Luso-Brasileiro Educação, Trabalho e Movimentos Sociais - das políticas às lógicas de ação (pp. 17-28). Lisboa: IEUL. 
Tedesco, J. (2000). O Novo Pacto Educativo - Educação, competitividade e Cidadania na Sociedade Moderna. Vila Nova de Gaia: Fundação Manuel.

Trigo, M. (2002). Balanço de um ano de atividade. In I. M. Silva, J. A. Leitão, \& M. M. Trigo (Orgs.), Educação e formação de adultos: Fator de desenvolvimento, inovação e competitividade (pp. 115-119). Lisboa: ANEFA.

UNESCO. (1997). V Conferência Internacional sobre Educação de Adultos. Declaração Final e Agenda para o Futuro. Hamburgo: Instituto de Educação da Unesco.

UNESCO. (2016). The Recommendation on Adult Learning and Education. France: United Nations Educational, Scientific and Cultural Organization and UIL. 


\section{(ANEXO UM)}

Figura 1 - Fases Principais do Processo de Reconhecimento de Adquiridos Experienciais

Formação Complementar Formação Exterior
Atendimento / Inscrição

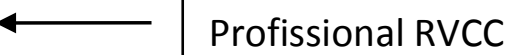

Entrevista
Profissional RVCC

Formadores

Formadores

Profissional RVCC

Formadores

Avaliador Externo

Certificação 